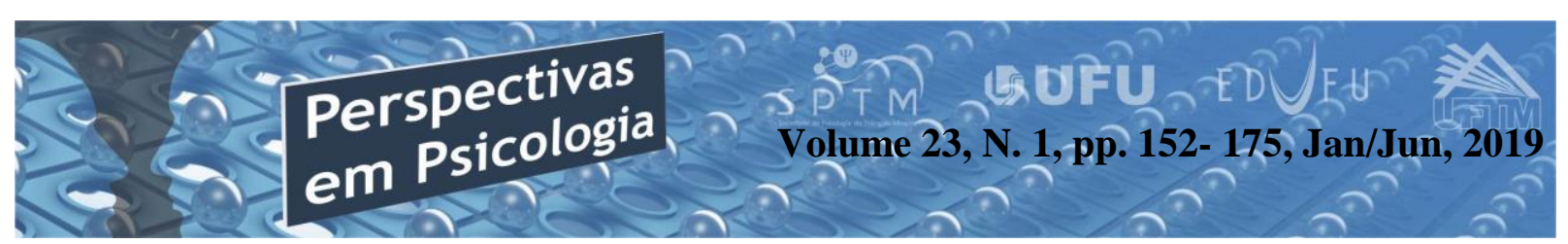

\title{
A HISTORICIDADE DO RACISMO E SUA MANIFESTAÇÃO NA COMUNIDADE QUILOMBOLA DO ATALHO
}

\author{
Andréa Aparecida Fernandes \\ Lara Gonçalves Moreira \\ Laura Maria Mota Rosa \\ Laurem Nayane Mundim Rosa \\ Vicente de Paulo da Silva \\ (Fundação Carmelitana Mário Palmério - FUCAMP, Monte Carmelo - MG).
}

\begin{abstract}
Resumo
O racismo no Brasil esteve presente desde muito cedo. Dessa forma, o objetivo deste trabalho é abordar o tema hoje na sociedade. Como metodologia foram utilizadas bibliografias que discorrem sobre o assunto, e visitas à uma Comunidade Quilombola, remanescente dos escravos, onde através de conversas informais com os moradores, contribuiu para o entendimento pratico do tema, ampliando os conhecimentos sobre os costumes, vivências, sentimentos e necessidades dessa população. Como resultado tem-se que mesmo muitas pessoas afirmando que o racismo não existe, foi possível verificar que sim, ele está presente, mesmo que não de forma exposta, ainda são muitas as pessoas que sofrem em diversas ocasiões, algumas mais extremas, chegando até à morte causada pelo ódio. Assim, essa população marginalizada por todos esses anos, continua resistindo para que permaneça a identidade afrodescendente, através de manifestos em busca de seus direitos.
\end{abstract}

Palavras-chave: Racismo; Negro; Escravidão; Quilombos.

\section{Abstract \\ The historicity of racism and its manifestation in the Quilombola Community of Shortcut.}

Racism in Brazil was present from a very early age. Thus, the objective of this work is to address the issue today in society. As a methodology, bibliographies were used on the subject, and visits to a Quilombola Community, a remnant of the slaves, where through informal conversations with the residents, contributed to the practical understanding of the theme, expanding knowledge about customs, experiences, feelings and needs of this population. As a result one has to say that many people affirmed that racism does not exist, it was possible to verify that yes, it is present, even if not in an exposed way, there are still many people who suffer on several occasions, some more extreme, death caused by hatred. Thus, this marginalized population for all these years, continues resisting so that the afrodescendant identity remains, through manifests in search of their rights.

Keywords: Racism; Black; Slavery; Quilomb. 



\section{Introdução}

O racismo no Brasil esteve presente desde muito cedo. Dessa forma, o objetivo deste trabalho é abordar o tema hoje na sociedade. Portanto, com o intuito de alcançar o tema em questão, apresentaremos inicialmente conteúdos sobre o momento em que começou a escravidão negra no Brasil e como funcionava nessa época; seguido de algumas resistências vividas pelos escravos em relação aos seus senhores, resultando no principal e maior quilombo - Quilombo dos Palmares- para tentar fugir da opressão e sofrimento vividos na escravidão; o acontecimento da abolição da escravatura, a partir da Lei Áurea de 1888, apresentando referenciais teóricos que discutam a situação dos negros pós escravatura, em uma tentativa de integração se eles realmente se tornaram livres e indivíduos com direitos iguais.

Seguindo para os conceitos sobre movimentos sociais negros, como intenção maior de abdicar direitos perdidos e de inserirem-se na sociedade, neste artigo, serão apresentadas as definiç̧ões do que são movimentos sociais e como eles são aplicados de maneira metodológica a nível internacional, mas principalmente voltado para marcos histórico-culturais do Brasil. Nomes e acontecimentos mais marcantes que influenciaram para que a etnia afroamericana seja de fato vista pelas políticas públicas e a população em geral, para que a humanização seja aplicada a todos, independentemente do fator étnico, socioeconômico e cultural.

Mostraremos a importância de discutir e pensar sobre o assunto, desde a definição e onde começou o racismo, até como ele acontece atualmente, mesmo que de maneiras disfarçadas por parte de muitas pessoas, até mesmo as de cargos importantes na sociedade, cargos e posições estes em que seria possível buscar a diferença e melhoria, ou mesmo a fomentação da discussão do assunto.

A partir do subtema Remanescentes de Quilombos, escolhido pelo grupo para realizar o trabalho de campo, de modo que contribuísse e conversasse com o tema principal, com embasamento teórico mostraremos como foi a formação dos quilombos e o modo de funcionamento dos locais, apontando as leis e decretos, das quais visam os direitos dessa população; complementando enfim com a pesquisa de campo realizada na Comunidade Quilombola, sendo mais específico, a chamada "Comunidade do Atalho" no município de Monte Carmelo - MG, formada no século $\mathrm{XX}$, onde conhecemos melhor os moradores, suas histórias e seus sentimentos em relação a situação em que vivem. 
Buscamos com este trabalho, levar todos a uma maior reflexão sobre a temática, analisando a forma como tratamos e vemos as pessoas ao nosso redor, dispensar atenção, cuidado e respeito, levando a consideração o caminho trilhado e a história de cada indivíduo.

\section{Escravidão no Brasil}

A maioria dos negros que vieram para o Brasil é proveniente de uma região do continente africano denominada de África subsaariana, ou seja, toda a parte do continente que está localizada abaixo do deserto do Saara, que apresentou um considerável desenvolvimento até a chegada dos europeus no século $\mathrm{XV}$ e XVI.

Sabe-se que na escravidão, o negro era considerado propriedade de outro indivíduo, que tinha posses, voz e poder, o escravo, podendo ser negociado, não tinha escolhas de vida melhor e nem direitos de nenhum tipo, como não poder possuir e/ou doar bens, iniciar processos judiciais, entre tantas outras questões. (Batista \& Carvalho, 2009)

Não existem registros precisos dos primeiros escravos negros que chegaram ao Brasil. A tese mais aceita é a de que em 1538, Jorge Lopes Bixorada, arrendatário de Pau-Brasil, teria traficado para a Bahia os primeiros escravos africanos. Eles eram capturados nas terras onde viviam na África e trazidos à força para a América, em grandes navios, em condições miseráveis e desumanas. Muitos morriam durante a viagem através do oceano Atlântico, vítimas de doenças, de maus tratos e da fome.

No século XVII, com a invenção das grandes fábricas, os países europeus procuravam terras novas para investirem em construções de fábricas e geração de matéria prima. Estes fatos coincidiram com a implantação da escravidão negra e a escravidão se intensificou nos anos de 1700 a 1822, sobretudo pelo grande crescimento do tráfego negreiro. $\mathrm{O}$ comércio de escravos entre África e Brasil tornou-se um negócio muito lucrativo.

Conforme explanado por Pinsky em seu livro, A escravidão no Brasil (2010), o regime escravista iniciara-se pouco depois da chegada dos europeus no Brasil, quando para conseguir lucros na extração do paubrasil passaram a escravizar os indígenas depois que o mecanismo de troca não mais os atraia. Porém, depois de algum tempo a mão de obra indígena não era mais vantajosa devido ao fato de não existirem pessoas suficientes, obedientes e de um custo baixo. Em consequência, os senhores começaram a procurar uma mão-de-obra 
mais barata, surgindo assim o tráfico de africanos para o Brasil, de forma compulsória realizavam o trabalho nas grandes lavouras.

Os escravos que sobreviviam à travessia, ao chegar ao Brasil eram logo separados do seu grupo linguístico e cultural africano e misturados com outros de tribos diversas para que não pudessem se comunicar. Seu papel de agora em diante seria servir de mão-de-obra para seus senhores, fazendo tudo o que lhes ordenassem, sob pena de castigos violentos. Além de serem trazidos de sua terra natal, de não terem nenhum direito, os escravos tinham que conviver com a violência e a humilhação em seu dia-a-dia. (Pinsky, 2010)

Ainda segundo Pinsky (2010, os escravizados não possuíam nenhuma lei que lhes fosse favorável, sendo condenados ao trabalho em condições desumanas onde não tinham local adequado para descansar ou se alimentar, recebiam açoites ou torturas se não obedecessem aos seus senhores. Crianças eram separadas de suas famílias ainda muito jovens e vendidas a outros senhores e várias outras situações de completa falta de empatia e respeito com o próximo.

Retirado do seu habitat, de sua organização social, do seu mundo, é natural que estivesse atemorizado de uma nova condição que, ao menos de início, nem chegava a compreender devidamente. Sem conseguir definir seu espaço social, sentia-se nivelado pelos captores dos demais cativos, oriundos de outras tribos, praticantes de outras religiões, conhecedores de outras línguas, vindos de outra realidade. Nem por isso, ele se identificava com outros cativos: sentia-se solto, perdido, sem raízes. Não entendia bem sua situação, reagindo com estupor e inércia às ordens. (Pinsky, 2004)

\subsection{Resistências à Escravidão: Palmares - O Maior Quilombo}

Visto o grande sofrimento vivenciado durante a escravidão, os indivíduos precisavam buscar alternativas para lidar ou acabar de vez com essas condições, tentavam, de forma pacífica, negociar, porém, na maioria das vezes, não obtendo o sucesso, necessitaram partir para atitudes mais drásticas, passando por inúmeras dificuldades, além das já existentes.

A história da resistência à escravidão é longa e dolorosa, marcada por grandes revoltas visando à liberdade do povo negro das amarras dos senhores. Desde uma pequena resistência cotidiana (fingimento de doenças, o trabalho mal feito e as estratégias de negociação para extrair pequenas vantagens de seus senhores) às fugas constantes. 
Autores como Reis e Silva (2009), mostram uma visão a respeito do sistema escravista, na qual os escravos faziam negociações com seus senhores, como por exemplo, trabalhar para si e acumular dinheiro para mais tarde comprar sua liberdade; mas nem sempre esse tipo de negociação funcionava. Desta forma, quando esse tipo de negociação falhava ou nem acontecia devido à intransigência senhorial, ou seja, quando as políticas escravistas não funcionavam, os caminhos da ruptura se abriam. A formação de Quilombos, magia, sabotagens, fugas, suicídios e roubos eram algumas das formas de resistência escrava. (Reis \& Silva, 2009)

Um dos mais importantes quilombos da Era Colonial brasileira foi o Quilombo dos Palmares. Ele se desenvolveu no final do século XVI na região da Serra da Barriga, antiga capitania de Pernambuco, localizado atualmente no estado de Alagoas. Além de abrigo para fugitivos, a origem do quilombo dos Palmares possui um contexto mais abrangente que é o da produção, distribuição e consumo do açúcar. Nota-se que o objetivo dos Holandeses e povos Ibéricos era encontrar formas de aumentar a produção de açúcar usando a mão-deobra escrava para facilitar todo o processo de distribuição e transporte para a Europa.
No início, o Quilombo dos Palmares compunha-se de escravos de origem angolana. Mas, nos 100 anos de existência do lugar outras pessoas se juntavam a população negra, como índios e brancos excluídos da sociedade. $\mathrm{O}$ auge do Quilombo dos Palmares foi na segunda metade do século XVII. De acordo com o artigo online 20 de novembro: data histórica viveram cerca de 20 mil pessoas antes da morte de Zumbi.

Não há como negar que as
comunidades palmarinas, dada a
extensão territorial e a quantidade de
escravos fugitivos que acolheram,
tornaram-se o maior quilombo na
história da América portuguesa.
(Marquese, 2006, p.110).

Pouco se sabe dos hábitos dos quilombolas pelo fato de não terem deixado escritos, mas sabe-se, de acordo com o livro Palmares, ontem e hoje (Funari,2005, p.12) que eram governados por um rei cujo nome era Ganga Zumba, que significa "grande chefe". Em Palmares se cultivava mandioca, feijão, batata, milho, legumes e cana de açúcar.

Em 1678, o governador Pedro de Almeida liberta alguns parentes que levam a Zumba uma proposta de paz. A proposta era de os quilombolas se mudarem para o Vale do Cacau e não aceitar mais escravos 
fugidos. Essa proposta dividiu os líderes dos mocambos, pois foi apoiada pelos que, como Ganga Zumba, estavam cansados das lutas, e rejeitada pelos líderes que desejavam continuar a lutar; entre estes últimos estava Zumbi, sobrinho de Zumba. Sem conseguir unanimidade, parte dos moradores decide abandonar o quilombo. A mestre em história do Brasil, Juliana Bezerra, em seu artigo biográfico sobre Ganga Zumba, diz que o mesmo percebe que foi enganado quando chega ao Vale de Cacau, as terras não eram boas, eram vigiados e sem liberdade para circular. A respeito da morte de Zumba, o livro Palmares, ontem e hoje (Funari,2005, p.12) afirma que seu sobrinho Zumbi se revoltou e o matou.

Zumbi dos Palmares liderou desde a morte de Ganga Zumba em 1678 até o fim da vida, em 1695. Zumbi possuía habilidades para guerra e conhecimentos militares; quando se tornou líder fortificou a sede de Palmares e preparou a resistência ao governo da Capitania de Pernambuco. (Santos, 1980). Iriam agora enfrentar cara a cara o inimigo, embora soubessem de sua superioridade militar. Deste modo, passaram-se vários anos em meio a guerras e tréguas.

Por fim, Domingos Jorge Velho foi chamado para organizar a invasão do quilombo. Em 6 de fevereiro de 1694 a capital de Palmares foi destruída e Zumbi ferido. No dia 20 de novembro de 1695, o líder Zumbi, do Quilombo dos Palmares, foi morto em uma emboscada após ser traído por um companheiro. Sua cabeça foi cortada e exposta em praça pública. (Geledés, 2009)

É interessante a conclusão de que toda essa guerra contra a escravidão soldava a solidariedade do povo, e assim era formada uma identidade quilombola. Além disso, era formado um modelo de economia autossustentável. Zumbi defendia um Brasil livre, liderado pelos Africanos; podemos dizer que esse era o verdadeiro sonho dele, valendo todos os sacrifícios e as lutas.

Foi Zumbi dos Palmares um caso extremo de resistência ao sistema,

[...] Desde que se sentou no trono que fora de Ganga Zumba, na praça central da Cerca Real do Macaco, seu corpo pequeno e magro se transformou numa flecha apontada para o coração do mundo escravista. (Santos, 1980, p.37)

Desde 2003, o dia 20 de novembro ficou conhecido com o Dia da Consciência Negra. A data foi estabelecida pelo projeto de Lei $\mathrm{n}^{\circ} 10.639$, quando foi instituído nas escolas do país o ensino da história e da cultura afro-brasileiras.

\subsection{Abolição do Regime Escravista}


Deve-se recordar que a escravidão no Brasil não acabou rapidamente, foi um longo processo gradual, com muitas fases envoltas por lutas árduas, até chegar a Lei Áurea, ainda assim, sabe-se que as implicações desse fato permeiam por nossa sociedade até os dias de hoje.

Algumas leis, conhecidas como "lei pra inglês ver", foram criadas como tentativa para promover e avançar os movimentos direcionados a abolição da escravatura, a primeira delas, Lei Eusébio de Queiróz, de 4 de setembro de 1850, a qual proibia o tráfico negreiro para $\mathrm{o}$ Brasil. As ações que caminharam para estabelecer essa lei começaram muito antes da década de 50, envoltas por tratados assinados por D. João a partir de 1810 e levando em conta às determinações resultantes das pressões da Inglaterra, somente em 1826 declaram-se livres todos os escravos vindos de fora do Império, porém, sem sucesso, o tráfico ainda continuou ativo. (Menezes, 2009)

Finalmente, após crises no relacionamento do Brasil com a Inglaterra, com os navios destas invadindo as águas territoriais brasileiras para aprisionar navios negreiros, em 1850 é aprovada a Lei Eusébio de Queiroz, para o combate ao tráfico clandestino. As medidas de repressão ao tráfico instaladas de aí até
1860 são de caráter econômico, criando-se taxas sobre os escravos, sobre sua transmissão, sua consignação; a sua venda é taxada pelo mesmo critério das "casas de moda".

Em 15 de setembro de 1869 se estabelece o decreto proibindo a venda de escravos debaixo de pregão e em exposição pública, dando mais um passo, mesmo que devagar, para alcançar a liberdade dos escravos, atingindo, talvez, o sentimento de vergonha de um ato com tanto sofrimento, como a escravidão, dando lugar a uma nova lei:

Determina então, a Lei do Ventre Livre, de 28 de setembro de 1871, em que os filhos de escravos, nascidos a partir dessa data, estariam livres, entretanto, isso acontecia somente quando o filho alcançasse a idade de 21 anos, até lá, permaneciam com os senhores, sendo explorado nos serviços da fazenda também.

Diante disso, Menezes (2009, p. 9091) "ressalta, nenhum dos ingênuos chegou a liberdade pelo mecanismo da Lei do Ventre Livre: quando da Abolição final, em 1888, tinham apenas de 16 para 17 anos os mais velhos".

Neste momento, parece ter ocorrido uma conformação, como se o que se estabeleceu até aqui já bastasse, apenas em 1879 a partir de um deputado baiano, 
professor da Faculdade de Medicina da Bahia e abolicionista, Dr. Jerônimo Sodré, que o assunto voltou a percorrer pela sociedade, diante da denúncia da lei de 1871, e fazendo um apelo para o fim total e rápido da escravatura. (Menezes, 2009)

Entre sistema parlamentar, movimentos das sociedades abolicionistas e seus debates e convenções, surge e indica a Lei dos Sexagenários ou Lei SaraivaCotegipe, de 28 de setembro de 1885, oferecendo, aparentemente, benefício e liberdade aos negros com mais de 60 anos, porém, vale lembrar que nem todos chegariam a viver até essa idade, e quando libertados, eram os que já eram menos valorizados, que renderiam mais despesas do que lucros, justamente pela idade avançada.

Enfim, com grande parte da sociedade se tornando a favor da abolição da escravidão, com o projeto apresentado no dia 8 e aprovado no dia 13 de maio de 1888, se institui a Lei Áurea, assinada pela Princesa Isabel, estabelecendo o fim da escravidão no Brasil, lembrando que isso não rompeu com a exploração do trabalho dos ex-escravos, a Lei Áurea, mesmo sendo um passo importante e decisivo, resolveu em termos subjetivos o problema da escravidão, já que os negros não receberam nenhum tipo de auxílio que colaborasse para a sua inserção na sociedade.

\subsection{A Integração do Negro na Sociedade Após a Abolição}

Segundo Fernandes (1978) a instituição formal da proibição da escravidão, com a Lei Áurea, oficializou o direito de liberdade para os negros, porém, não significou, a princípio, seu acesso aos direitos, nem o fim de sua segregação na sociedade.

A imigração europeia e a evolução urbana, impulsionadas pelo capitalismo, mercantilismo e industrialização produziram a marginalização dos excativos, econômica, social e profissionalmente. O despreparo moral, intelectual, profissional e material tornavam os recém-libertos completamente desadaptados à sociedade urbana, o que lhes ocasionou enorme sofrimento psíquico. Os centros urbanos formavam-se cada vez mais "burgueses", com mentalidade mercantil. (Fernandes, 1978).

Após a Abolição ocorreu a formação de dois blocos distintos dos negros: os chamados "negros da casa grande" e os "negros do eito", uns ligados aos serviços das famílias na área urbana e os outros ligados ao serviço rural nas fazendas. Mesmo tendo ambos vivenciado a condição de escravos, não trilharam o mesmo caminho. Estes últimos, desligados das fazendas tiveram uma história mais 
degradante, tendo em vista que suas vivências como escravos foram através do trabalho rústico da lavoura e só isso sabiam fazer (Fernandes, 1978).

Neste cenário, conforme Nunes (2008 apud Fernandes, 1978), as mulheres tiveram mais sucesso na busca por trabalhos. Umas domésticas, outras trabalhando como lavadeiras, engomadeiras, costureiras (em suas próprias moradias), entre outras ocupações passaram a ser quase que totalmente as provedoras dessa parte do "elemento negro" na condição de "servidão disfarçada" (Fernandes, 1978).

Conforme explanado por Feldman (2015) os desajustamentos encontrados nos negros, em geral, apontam para um anseio de participação na vida social e econômica da sociedade inclusiva "como gente". O estilo de vida burguês individualista e competitivo do convívio urbano era incompatível com as formas de vida rústicas daqueles povos despreparados e desamparados pelo poder público. Questionamentos feitos por Feldman (2015) incluem: como fazer parte de um momento histórico de uma sociedade sem participar como agente de criação e reprodução desta? Como preparar os jovens para viver num espaço de segregação, esperando e desejando sua ascensão social, mas ao mesmo tempo tendo que protegê-los dos perigos que iriam enfrentar no contato perigoso com os negros "não-ordeiros" e seu convívio com os brancos?

A organização da vida do negro dependia do desenvolvimento econômico e social, entretanto, as oportunidades que tinham não eram compatíveis com suas necessidades. E, por outro lado, os negros e mulatos sofreram a falta de escolarização. As crianças não eram colocadas na escola por vários motivos, inclusive, com o intuito de que esses não viessem a se desapontar no futuro quando percebessem que seus sonhos tinham limites e apostar muito alto além de suas possibilidades reais era perda de tempo. (Feldman, 2015).

Quase meio século havia se passado e os negros, em sua maioria, ainda não haviam conseguido delimitar um espaço para si na sociedade capitalista; em contrapartida, os imigrantes já haviam se instalado e conquistado espaços importantes para si e para seus descendentes. (Feldman, 2015).

A Constituição de 1891 celebra igualdade jurídica a todos os brasileiros. No entanto, não dá as condições para que a democracia se realize de forma ampla. Dessa forma, a igualdade jurídica não significará muita coisa para o negro que 
continuará sofrendo a desigualdade real e cruel. (Fernandes, 1978).

Em suma, respaldados em Fernandes (1978), constata-se que, nas relações entre as classes sociais, nas relações interpessoais e intrapessoais, sempre estiveram presentes as marcas herdadas da escravidão, evidenciando uma integração social do negro em meio a uma sociedade de classes, patrimonialista, capitalista, intelectualista e, veladamente ou não, em muitos âmbitos, racista.

\section{Movimentos Sociais Negros}

Ao longo de toda a narração afrodescendente na história mundial, desde seus tempos coloniais até contemporâneos, as relações de poder são impostas a tal sociedade marginalizada, retirada de seu lar por desconhecidos que portavam além de armas sua ganância e legitimidade ignorante. A partir dessa retirada abrupta da própria liberdade, da vontade de se sentirem verdadeiramente inseridos na sociedade e terem direito a tê-lo, surgem os movimentos e ativismos sociais, nos quais não só negros, mas em termos atuais, as tribos urbanas e sociais utilizam como tentativa de sua voz ser ouvida e seus direitos serem vistos pela sociedade normativa, tanto de modo direto quanto indireto.
Em uma primeira instância, para que se desenvolva a historicidade de tais, o conceito deve ser dado. Os movimentos sociais são vistos de diferentes formas em diferentes vertentes de conhecimento.

De acordo com Honneth (2003), os movimentos sociais são ações de caráter grupal que tem como objetivo manter ou mudar uma determinada condição. Os movimentos sociais deixaram de ser taxados no meio sociológico como meramente respostas com cunho desrespeitoso e rebelde a determinado poder, contexto, padrão, ou qualquer imposição; e os motivos para a rebelião, protesto e resistência passaram a ser vistas como algo que possui interesses independentes que vão de encontro as iniquidades identificadas por determinados grupos sociais.

O segundo ponto é para que esse fenômeno social se finde, precisa-se de uma variabilidade de níveis coletivos, com diferentes valores hierárquicos e que essa elevação social seja reivindicada pelas camadas inferiores da sociedade, ou que no momento estão em uma posição abaixo dos demais. O declínio que pode acontecer devido aos problemas nas bases dos canais influencia na dificuldade de formar a tensão que gera as revoltas sociais geradoras de voz ao povo estratificado. (Tavares, 2013) 
Assim, retomando momentos histórico-culturais, como citado em capítulos anteriores, após a extinção dos quilombos, caracterizados como símbolos de resistência negra; e posteriormente, a abolição da escravidão no Brasil instituído por lei, e a proclamação da república. A história passava diante os olhos da população negra que após serem "libertos" se viram sem nenhum amparo social, o que lhes foi instituído criar sua própria autonomia através de seus feitos, gerindo novos grêmios, clubes, associações e até mesmos jornais que dessem voz ativa ao povo que foi, em termos mais crus, jogados na sarjeta com sua emancipação como único apoio. (Domingues, 2007)

No Brasil, época da ascensão Getulista, com a polarização dupla das políticas (direita e esquerda), os negros ainda não faziam parte da parte nem da população "liberal", nem da elite conservadora, continuando como um grupo ímpar de todos os confrontos nacionais e no limbo da integralidade. Foi dessa imposição que um grupo de pessoas criaram a Frente Negra Brasileira (FNB), aprovado no Salão das Classes Laboriosas (Domingues, 2008).

A FNB foi um movimento muito simbólico que incentivou protestos e marchas, constituindo mais de 100.000 negros a lutarem pelos seus direitos. Tal fundação teve grande impacto mundial, colocando esses movimentos nas capas iniciais dos jornais americanos, que na época, enfrentavam as leis de Jim Crow, a declaração da segregação social e terrorismos ao povo negro instigados pelo grupo supremacista, $K u$ Klux Klan. (Domingues, 2013).

Ainda ao nível nacional, outro marco para a representatividade negra ainda mais vívida na sociedade, além das revoluções jornalísticas que influenciaram todo o Brasil foi a criação do Teatro Experimental do Negro (TEN), em 1944. Essa fundação foi um símbolo de debate a frente à Constituição de 1946, promulgada por Vargas após o golpe de estado liderado por este. Tal carta política reabriu os parlamentos antes fechados pelo Estado Novo, e veio com o pretexto de que o Brasil não tinha ligação nem muito contato com o exterior, o que facilitou a entrada e polarização do regime comunista e conservador. (Ferreira, 2010)

A Frente Negra Brasileira abriu portas não somente para a etnia em questão deste artigo. Suas lutas ultrapassaram a cor e origem, indo ao encontro da integração de outros povos que habitavam o Brasil dando sua característica multicultural única. As mobilizações causaram impacto em todos os canais verticais da sociedade brasileira. (Domingues, 2008). O Jornal $A$ 
Voz da Raça, um dos maiores meios jornalísticos negros da época retrata em um trecho de suas matérias o progresso das lutas:

Hoje, mais do que nunca, um sentido ecumênico se funde nas manifestações públicas. Se aqui vedes pretos e brancos irmanados e solidários, ide à sede de uma das organizações que nos dão este espetáculo - a Frente Negra Brasileira - e vereis como sinal dos tempos, cursando as suas aulas, nacionais brancos, europeus e até japoneses. (A Voz da Raça, 1937, apud, Domingues, 2008)

Como relatado por Bentes (2002), depois de muita burocracia e boicotes, o Brasil conseguiu representatividade e participar da tão importante conferência que era um banho inigualável de culturas diversas que lutavam por uma mesma causa. Atualmente, uma grande parcela da população mundial se encontra ainda em posições de segregamento social e intelectual, são expostas e tem um contato muito violento com o racismo que parece evoluir mesmo depois de tantos anos de resistência, consequentemente, os movimentos negros ainda são muito vívidos nas culturas que ainda lutam pela essência e pelo principal objetivo de toda a resistência: Seus direitos.

\section{Racismo}

Segundo a definiç̧ão do Dicionário Aurélio de língua portuguesa (2018, p. 578) racismo consiste: "Racismo substantivo masculino 1. Conjunto de teorias e crenças que estabelecem uma hierarquia entre as raças, entre as etnias. 2. Doutrina ou sistema político fundado sobre o direito de uma raça (considerada pura e superior) de dominar outras."

Dessa forma o racismo seria a crença na existência de raças superiores, traduzindo em miúdos trata-se da superioridade do branco sobre os nãobrancos (pretos, pardos, indígenas, amarelos), muitos defendem que se trata de uma característica inata do ser humano, porém, não seria uma construção histórica e social criada a partir das diversas relações?

O Brasil foi o último país da América latina a abolir a escravidão, e o mesmo que durante a época escravista mais recebeu pessoas como mercadoria da África, cerca de 10 milhões segundo pesquisas realizadas pela Universidade de Emory, em Atlanta, nos Estados Unidos, e de Hull, na Inglaterra, divulgadas em 2008.

Em contrapartida o Brasil é considerado hoje o país com maior população negra fora da África, segundo Pesquisa Nacional por Amostra de Domicílios Contínua 2016, divulgada em fevereiro de $2017,54,9 \%$ da população é negra, importante frisar que o conceito de 
negro para o IBGE consiste na autodeclaração de ser preto ou pardo.

Território negro, Mocambos, Terras

Recentemente foram criados dois conceitos que atingem muitas vítimas do preconceito racial, a vitimização e o racismo reverso, porém é evidente a inexistência na prática desses termos, visto que o racismo não se trata de uma implicação pessoal, mas de uma estruturação social que sempre oprimiu negros em benefício de brancos, o que é suscetível de ocorrer em qualquer movimento é o radicalismo, que de forma alguma desmerece as mobilizações sobre o assunto. Importante ressaltar que a única pessoa capaz de determinar o que considera discriminação racial é a própria vítima.

$\mathrm{O}$ fomento pelo debate político e público talvez tenha sido o momento mais imprescindível e auspicioso para conhecimento e busca de deliberações a respeito das relações raciais no Brasil, permitindo buscar medidas capazes de enfrentas o racismo e buscar igualdade de oportunidades. Faz se necessário que essa argumentação atinja todos os níveis da sociedade, para que seja possível um entendimento sobre as diversas formas de discriminações sofridas.

\section{Formação e Funcionamento} dos Quilombos

Diversas são as definições que de alguma forma buscam aproximar-se dos acontecimentos vivenciados pelos habitantes dessas comunidades e da realidade em que habitam hoje em dia.

Não se sabe ao certo como o termo ‘quilombo' passou a ser usado no Brasil, porém, segundo registros, mesmo que com sentidos diferentes dependendo da época e da região, a palavra quilombo passou a fazer parte do Brasil e toda a América pelos negros africanos escravizados, em média $40 \%$ deles tiveram o Brasil como destino, sendo os primeiros a chegarem em 1554.

A palavra quilombo possui uma conotação que envolve migrações, alianças e guerras em que homens, membros que não se distinguem por filiação ou linhagem, eram submetidos aos rituais de iniciação. Esses rituais os retiravam da proteção de suas linhagens e os integravam em uma organização como co-guerreiros e super-homens imunes às armas de seus inimigos. (Calheiros \& Stadtler, 2010, p. 135)

Vale lembrar que o termo quilombo só aparece na documentação colonial no 
final do século XVII. Como já mencionado neste trabalho, as conhecidas comunidades quilombolas serviram de refúgio para inúmeros escravos que se juntaram e arriscaram com o intuito de sair da opressão e sofrimento dos quais viviam há tempos com a escravidão.

Surgiram tantos fugitivos em busca de apoio nos quilombos, já espalhados por toda parte, que as autoridades coloniais começaram a chamá-los de "contagioso mal".

Os quilombos são a materialização da resistência negra à escravidão, foram uma das primeiras formas de defesa dos negros, contra não só a escravização, mas também à discriminação racial e ao preconceito. (Silva, 2012, p. 6).

De modo geral, os grupos se formam a partir da identificação da cultura de valores, histórias, costumes religiosos, interesses; portanto a comunidade quilombola não seria diferente, os sujeitos inseridos compartilhavam de aspectos dos quais os levavam a um passado com vivências em comum.

Porém, é válido lembrar, segundo Freitas, 1984 (apud, Furtado et e al, 2014, p. 111) que, "apesar da predominância de negros, os quilombos se constituem como espaços interétnicos habitados por indígenas e até por brancos em situações de extrema pobreza e exclusão". Sendo assim, os moradores dos quilombos abrigavam, quando necessário, outras pessoas em condições de extrema necessidade, independente se faziam parte do grupo cultural deles.

Dentro do possível, o quilombo começou a ser o espaço onde eles podiam viver e reafirmar suas raízes culturais, colocando em prática todos os seus costumes, permitindo que eles sentissem e assumissem suas verdadeiras identidades, tanto individuais, quanto compartilhadas referentes ao grupo. (Furtado et e al, 2014)

O ano de 1988 é marcado por muitas conquistas em que aos poucos as comunidades remanescentes de quilombo conquistaram mais visibilidade, começando pelo centenário da abolição da escravatura, a promulgação da Nova Constituição do Brasil e a criação da Fundação Cultural Palmares (FCP), vinculada ao Ministério da Cultura, sendo a primeira instituição pública federal que visa promover e preservar a arte e cultura afro-brasileira, lutando por uma política cultural igualitária e inclusiva.

\section{Pesquisa de Campo: Comunidade do Atalho (Monte Carmelo - MG)}

A partir do trabalho de campo proposto na disciplina de Psicologia 
Social, contamos com a oportunidade, por meio do auxílio de profissionais do Centro de Referência de Assistência Social (CRAS) Mãe do Leu", anexo Lagoinha, bairro de Monte Carmelo, de conhecer alguns moradores de uma das comunidades quilombolas existentes, localizada no município de Monte Carmelo-MG.

A Comunidade do Atalho surgiu no início do século XX, período pós-abolição da escravidão, época da qual surgiu grande parte das comunidades quilombolas de Minas Gerais. A totalidade correspondente ao território dessa coletividade é de três alqueires com aproximadamente oito quilômetros de distância da cidade de Monte Carmelo.

Segundo Rezende, Nunes e Tomé (2015) o nome Comunidade do Atalho se baseia no fato da comunidade ter um atalho cortando sua terra para que o caminho até o distrito de São Felix, que se localiza no município de Estrela do Sul, pudesse ser encurtado para facilitar o percurso na época áurea dos garimpos na região. $\mathrm{O}$ local também é conhecido por outros nomes como "lá nos crioulos", "lá nos pretos", vale lembrar que estes são nomes dados por moradores da cidade e até mesmo pelos vizinhos da comunidade.

Desde já, vale ressaltar que optamos por não adotar um questionário com estrutura específica durante nossas visitas à comunidade, percebemos que seria mais agradável aos moradores, abordar todos os temas a partir de uma conversa informal.

Ao chegarmos à Comunidade do Atalho fomos recebidos de forma muito acolhedora, conhecemos alguns dos moradores, e dois deles nos fizeram companhia durante todo tempo nas vezes em que visitamos o atalho; as suas moradoras de maneira muito prestativa nos contaram um pouco sobre a história do atalho e também de suas vidas e famílias.

Elas são irmãs e ao todo completam nove irmãos, alguns deles falecidos, um morando na casa ao lado, e o restante vive na cidade de Monte Carmelo, mas continuam sempre se encontrando. As duas irmãs moram desde seu nascimento na Comunidade do Atalho e ao serem questionadas sobre mudar para a cidade, uma delas afirma querer mudar, segundo ela, para "dar um tempo" do lugar, logo em seguida confortando a si mesma afirma: Tem que levar a vida é aqui mesmo... ou boa ou ruim é aqui.

Ao conhecermos os arredores da comunidade, notamos que todas as casas são próximas, sendo assim, quando necessário, um ajuda o outro, porém, cada um tem sua casa e sua plantação separadas. Observamos também que nos dias de hoje as residências são todas de alvenarias, 
diferente da primeira e segunda geração que moravam em casas popularmente conhecidas como "pau-a-pique"; durante a conversa uma moradora nos contou que as casas de antigamente eram mais frescas que as de hoje em dia.

A construção de casas de alvenaria começou com o incentivo da Fundação Nacional de Saúde (FUNASA) em decorrência do combate ao barbeiro e contou com a parceria da Prefeitura Municipal de Monte Carmelo, esta contribuiu com doações de materiais de construção para moradores da terceira geração. Vale lembrar que ainda existe em algumas casas o chão batido (chão de terra).

Fica nítido que mesmo após vários avanços os integrantes da terceira geração mantêm tradições deixadas pelos povos mais antigos, algumas bem visíveis como coar café com garapa e adoçar com rapadura, cozinhar no fogão a lenha, usar pilão de tronco de árvores para limpeza de grãos, fazer farinha, entre outros.

Comportamentos também são seguidos de uma geração à outra, comprovamos isso com os fatos que conhecemos a partir das histórias contadas, como a infância das duas irmãs, que desde esse período já ajudavam a mãe no trabalho, sendo o pagamento feito através de trocas e não por dinheiro, por exemplo, às vezes recebiam um pouco de arroz em troca dos serviços feitos, como varrer o terreiro, lavar lençóis. Essa prática foi passada também para os filhos das moradoras, que as acompanhavam para a colheita de café desde muito cedo, pois era a única maneira que elas tinham para continuar colhendo café, já que qualquer tempo sem trabalhar significava mais falta de dinheiro.

Como as grandes fazendas que rodeiam a comunidade necessitam de mão de obra para o trabalho realizado, até mesmo trabalhos pesados em colheitas, fazendo uso de ferramentas como machados e foices, vários dos habitantes da comunidade do atalho usufruem da temporada de colheita e manutenção para trabalhar fora de suas terras, visando auxílio na renda familiar. Atualmente, predomina pelas grandes fazendas da região, o cultivo de soja, café, granjas de aves e porcos, gado de corte, tomate e pimenta.

Em nossa primeira visita, as irmãs afirmaram que os serviços estavam em falta, por não estar na temporada de colheita, e as buchas que elas comercializam também possuírem época certa para serem confeccionadas; felizmente, na nossa segunda visita, a plantação e colheita de pimentas já estavam sendo realizadas. Próximo à comunidade se localiza uma grande represa 
que possui suporte para o abastecimento e irrigação de suas plantações.

Ainda abordando sobre a parte financeira, uma das irmãs expressou seus sentimentos em relação às dificuldades, reconhecendo que às vezes passam por tempos difíceis decorrentes da falta de trabalho, mas frisam que não acontece só com eles do Atalho, e sim que as dificuldades estão presentes em todos os lugares. Importante complementar, que a Comunidade do Atalho recebe do CRAS de Monte Carmelo, um benefício eventual, isto é, acontece em momentos de vulnerabilidade social, recebendo cestas básicas; segundo as moradoras, é um mantimento que ajuda muito todos eles. Tornou-se emocionante e reflexivo o momento em que ouvimos a conclusão da moradora sobre o assunto: Agora não... do jeito que nois é agora pode falar que nois é rico... em vista do que nois era... não pode é adoecer o resto nois dá um jeito.

Questionamos sobre os momentos em que paravam o trabalho e tinham algum tempo para se divertirem, relatam que há um tempo elas saiam para as festas, porém, após começarem a frequentar a igreja evangélica, nos momentos de descanso e em que estão na cidade, elas vão ao culto na igreja, e em alguns dias específicos o culto também acontece na comunidade, com todos reunidos.
Momento também de muita importância para a comunidade é a reunião com o intuito de resolver todos os assuntos pendentes sobre o local e as necessidades de cada um; no início reuniam-se a Comunidade do Atalho juntamente com a equipe de profissionais do CRAS e Empresa de Assistência Técnica e Extensão Rural do Estado de Minas Gerais (EMATER), entretanto, após a proposta de que os residentes continuassem as reuniões todo mês apenas entre eles, surgiram algumas dificuldades em colocar em prática.

Como mencionado neste trabalho, após os decretos regulamentando os direitos da população quilombola, algumas assistências foram oferecidas; no caso da Comunidade do Atalho, podemos citar alguns, obteve-se energia elétrica, fruto de um dos programas oferecidos a partir do Programa Brasil Quilombola, Luz para Todos do Governo Federal.

A conquista do território, embora seja primordial, muitas vezes não é suficiente para manter ou ampliar o desenvolvimento socioeconômico das comunidades, é necessário também financiamento de projetos, auxílios técnicos, incentivos à produção em bases sustentáveis, etc., ou seja, que estas populações sejam inseridas em um 
planejamento de políticas públicas de longo prazo. (Silva \& Nascimento, 2012)

O projeto Bolsa família é mais um dos programas oferecidos e citado pelas moradoras, uma delas, por um curto período, conseguiu receber, e outra tentou por repetidas vezes e segundo ela, as pessoas envolvidas no processo desse programa pediam para que ela aguardasse, mas sem sucesso. Diante das dificuldades financeiras em relação às condições oferecidas aos filhos, tornou-se a única solução a saída deles da escola para começarem a trabalhar.

Com a oportunidade para expressar suas ideias sobre o assunto, uma das irmãs, que não conseguiu entrar no programa Bolsa Família, abordou sobre hoje em dia não ser permitido crianças e adolescentes menores de dezoito anos trabalharem, complementando que atualmente não tem mais crianças na comunidade, pois todos já estão "criados", ela finaliza sua fala desabafando os motivos das filhas saírem da escola sem concluir o ensino: Elas queriam as coisas... 'nois não tinha' não tinha como comprar nada ai 'nois tirou' elas da escola e colocou no serviço.

Segundo as moradoras do Atalho, no início, a EMATER ajudava, na medida do possível, suprir as necessidades da comunidade, visando melhores condições de vida, entretanto, o maior reconhecimento do local foi a partir da visita feita em 2015 pelos estudantes de Ciências Sociais da Universidade Federal de Uberlândia, e desde então a Comunidade do Atalho recebe mais assistência.

Após o reconhecimento da Comunidade do Atalho, às vezes os moradores recebem visitas de pessoas de vários lugares (Uberlândia, Brasília, Bahia, África) com a finalidade de recolher dados, verificar e comprovar a existência do local, reconhecendo e registrando legalmente, com todos os direitos prescritos.

Ainda em 2015, em fevereiro, iniciou-se o projeto de Geração de Renda, por meio do qual a Comunidade do Atalho começaria a comercializar buchas de banho artesanal, iniciativa feita pela Equipe Volante CRAS Mãe do Leu, por meio da assistente social da EMATER de Monte Carmelo.

Portanto, além dos trabalhos esporádicos nas fazendas vizinhas, os moradores da comunidade realizam vários trabalhos em suas próprias terras, por exemplo, o cultivo de pimentas, azeite de mamona, açafrão, mandiocas, milho, feijão, amendoim e bucha vegetal, sendo o produto mais comercializado deles. A venda é regularizada e possui selo, feito pela UFU e o CIEPS, identificando e comprovando a Comunidade do Atalho como fabricantes, a partir disso é gerada a 
renda da população da comunidade, visando melhoria da condição financeira.

De modo geral, podemos concluir que os negros quilombolas da Comunidade do Atalho alcançaram muitas conquistas nos últimos tempos a partir das leis estabelecidas oficializando seus direitos, notam-se alguns aspectos conquistados de fato na prática, outros ainda apenas na teoria, por isso é necessário saber que é uma luta contínua, e que nós como futuros psicólogos possamos auxiliar para que os progressos direcionados as comunidades quilombolas sejam alcançados.

\section{Conclusão}

O racismo, envolto por discriminação, preconceito, ódio; é um tema árduo, sendo possível a partir das várias referências usadas e das visitas à comunidade um entendimento maior a respeito, e o começo de um grande trabalho como psicólogos. Contudo, um trabalho como seres humanos, treinando nosso olhar para todos ao nosso redor, independentemente de suas raças, gêneros ou crenças.

O trabalho de campo foi indispensável, em que a partir de sua realização tornou-se visível o sofrimento no silêncio e olhar de pessoas as quais passaram por uma longa estrada lutando contra o racismo. Em um dos momentos que conversamos com as moradoras do Atalho questionamos a respeito do racismo, ambas permaneceram com uma expressão triste, e disseram que é lamentável serem tratadas como diferentes, devido à cor da pele. Entretanto, apesar de todo o tormento vivido por elas, é possível conhecer seus lados de muita garra, sem desistir da luta e dos seus direitos, durante muitas gerações.

Concluímos nossa atividade destacando a importância deste trabalho para nossa formação como psicólogos, a magnitude do assunto nos fez refletir até que ponto o racismo está enraizado em nossa sociedade, e o que podemos fazer para mudar isso, também nos levou ao conhecimento e divulgação de uma comunidade que vive vítima da invisibilidade social, algo que foi sustentado durante todas as conversas com as moradoras, por fim, esperamos que a partir da realização deste trabalho a Comunidade do Atalho, terra dos Crioulos se torne mais conhecida e renomada. 
ANDRÉA APARECIDA FERNANDES, LARA GONÇALVES MOREIRA, LAURA MARIA MOTA ROSA,

\section{Referências}

Bentes, N. Brasil--Durban--Brasil: um marco da luta contra o racismo. Revista Estudos Feministas. $\quad$ v. $10, \quad$ n. $1, \quad$ p. 229-236, 2002. https://doi.org/10.1590/S0104$026 \times 2002000100017$.

Calheiros, F.P. \& Stadtler, H. H. C. (2010). Identidade étnica e poder: os quilombolas nas políticas públicas brasileiras. Revista Katálysis , 13 (1), 133-139. Recuperado em 04 de maio de 2018 de: https://dx.doi.org/10.1590/S1414-49802010000100016

Comissão Pró-Índio de São Paulo (2013). Quilombolas Contemporâneos: quem são. Recuperado em 08 de maio de 2018 de: http://www.quilombo.org.br/quilombolas-quemsao.

Conselho Federal de Psicologia. Relações Raciais: Referências Técnicas para Atuação de Psicólogas/os. Brasília: CFP, 2017.

Decreto $\mathrm{n}^{\circ}$ 4.887, de 20 de novembro de 2003. (2003). Recuperado em 05 de maio de 2018 de: < http://www.planalto.gov.br/ccivil_03/decreto/2003/d4887.htm>

Decreto $\mathrm{n}^{\circ}$ 6.261, de 20 de novembro de 2007. (2007). Recuperado em 05 de maio de 2018 de: < http://www.planalto.gov.br/ccivil_03/_ato2007-2010/2007/decreto/d6261.htm>

Diário Oficial do Estado de São Paulo. (1931) p. 12. Revista Jus Brasil. Recuperado em 12 de maio de 2108 de: https://www.jusbrasil.com.br/diarios/DOSP/1931/11/04

Domingues, P. (2007). Movimento negro brasileiro: alguns apontamentos históricos. Tempo, 12 (23), 100-122. Recuperado em 12 de maio de 2018 de: <https://dx.doi.org/10.1590/S1413-77042007000200007>.

Domingues, P. (2008). Um "templo de luz": Frente Negra Brasileira (1931-1937) e a questão da educação. Revista Brasileira de Educação, 13(39), 517-534. Recuperado em 13 de maio de 2018 de: https://dx.doi.org/10.1590/S1413-24782008000300008. 
Domingues, P. (2013). Como se fosse bumerangue: Frente Negra Brasileira sem circuito transatlântico. Revista Brasileira de Ciências Sociais, 28 (81), 155170. https://dx.doi.org/10.1590/S0102-69092013000100010.

Feldman, R.S. Introdução à Psicologia, 10a ed. São Paulo: Amgh, 2015.

Fernandes, F. A integração do negro na sociedade de classes. 3. ed. São Paulo: Ática, 1978, v. 1.4

Fernandes, F. Significado do protesto negro. São Paulo: Cortez: Autores Associados, 1989, v. 33. Recuperado em 10 de maio de 2018 de: https://ayrtonbecalle.files.wordpress.com/2015/07/florestan-fernandes-o-significado-doprotesto-negro.pdf.

Ferreira, M. C. Rev. Bras. Polít. Int. 53 (2): 23-48, 2010. https://doi.org/10.1590/S003473292010000200002

Funari, P.P.A. \& Carvalho, A.V. Palmares, ontem e hoje, Jorge Zahar Editor, Rio de Janeiro: 2005, pp. 74 - ISBN 85-7110-875-7.

Fundação Cultural Palmares. (2012) Lei Afonso Arinos completa 61 anos. Recuperado em 30 de abril de 2018 de: http://www.palmares.gov.br/archives/21349.

Furtado, M. B, Pedroza, R. L. S., \& Alves, C. B.(2014). Cultura, identidade e subjetividade quilombola: uma leitura a partir da psicologia cultural. Psicologia \& Sociedade, 26 (1), 106-115. Recuperado em 30 de abril de 2018 de: https://dx.doi.org/10.1590/S010271822014000100012 .

Honneth, A. Luta por reconhecimento: a gramática moral dos conflitos sociais. São Paulo: Editora 34, 2003. 
IBGE. Síntese de Indicadores Sociais 2007. Recuperado em 02 de maio de 2018 de: <https://ww2.ibge.gov.br/home/estatistica/populacao/condicaodevida/indicadoresminimo s/sinteseindicsociais2007/default.shtm>.

IBGE. Pesquisa Nacional por Amostra de Domicílios Contínua. (2017) Recuperado em 08 de maio de 2018 de: https://agenciadenoticias.ibge.gov.br/media/com_mediaibge/arquivos/977bf8873975696b 9d8d67e305b6beb9.pdf.

INFOPEN. Levantamento Nacional de Informações Penitenciárias (2016). Recuperado em 02 de maio de 2018 de: http://depen.gov.br/DEPEN/depen/sisdepen/infopen/relatorio_2016_22-11.pdf.

IPEA. Mapa da Violência. DF: 2017. Recuperado em 04 de maio de 2018, de https://www.ipea.gov.br/portal/images/170602_atlas_da_violencia_2017.pdf/

Leis. Recuperado em 10 de maio de 2018 de: http://www.planalto.gov.br.

Marquese, R. B. (2006). A dinâmica da escravidão no Brasil: resistência, tráfico negreiro e alforrias, séculos XVII a XIX. Novos estudos CEBRAP, (74), 107-123. Recuperado em 10 de maio de 2018 de: https://dx.doi.org/10.1590/S0101-33002006000100007.

Menezes, J. (2012). Abolição no Brasil: a construção da liberdade. Revista HISTEDBR Online, 9(36), 83-104. Recuperado em 15 de novembro de 2018 de: https://doi.org/10.20396/rho.v9i36.8639642.

Moura, C. Rebeliões da senzala. São Paulo: Livraria Editora Ciências Humanas, 1981.

Moura, G. Navio Negreiro-Batuque no Quilombo. CNNCT. São Paulo, 1996.

Nunes, G. P. de A. N. (2012). “A integração do negro na sociedade de classes": uma difícil via crucis ainda a caminho da redenção. Revista Cronos, 9(1). Recuperado em 05 de maio de 2018 de https://periodicos.ufrn.br/cronos/article/view/1805. 
Pinto, S. M. R. (2007). Justiça transicional na África do Sul: restaurando o passado, construindo o futuro. Contexto Internacional, 29 (2), 393421. https://dx.doi.org/10.1590/S0102-85292007000200005.

Pompeu, A. (Correio Braziliense) (2014). Brasileiros acham que há racismo, mas somente 1,3 se consideram racistas. Recuperado em 03 de maio de 2018 de: https://www.ceert.org.br/noticias/outros/4473/brasileiros-acham-que-ha-racismo-massomente-13-se-consideram-racistas

Prado, F. K. (2011). Para uma arqueologia da psicologia social. Psicologia \& Sociedade, 23 (3), 464-468. Recuperado em 11 de maio de 2018 de: https://dx.doi.org/10.1590/S0102-71822011000300003.

Pinsky, J. (2004). A Escravidão no Brasil. 12ª ed. São Paulo: Contexto.

Reis, J. J.; Silva, E. Negociação e conflito: a resistência negra no Brasil escravista. São Paulo: Companhia das Letras, 2009.

Rezende, L. F. de; Nunes, N. P.; \& Tomé, V. P. Comunidades Remanescentes de Quilombo, Terra de Preto, Terra de Crioulos? Uberlândia: 2015.

Santos, J.R. Zumbi. São Paulo: Editora Moderna, 1980.

Sarmento, D. Territórios Quilombolas e Constituição: A ADI 3.239 e a Constitucionalidade do Decreto 4.887/03. Ministério Público Federal - Procuradoria Regional Da República $2^{\text {a }}$ Região. Rio de Janeiro: 2008. Recuperado em 08 de maio de 2018 de: https://www.saude.rj.gov.br

Secretaria de Políticas de Promoção da Igualdade Racial - SEPPIR. Programa Brasil Quilombola. Brasília, DF: 2013. Recuperado em 08 de maio de 2018 de: < http://www.seppir.gov.br/portal-antigo/arquivos-pdf/guia-pbq> 
Silva, S. R. Quilombos no Brasil: A Memória como forma de reinvenção da identidade e territorialidade negra. São Paulo: 2012. Recuperado em 02 de maio de 2018 de:< http://www.ub.edu/geocrit/coloquio2012/actas/08-S-Rezende.pdf>

Silva, S. R; Nascimento, L. K do \& Silva, S. R. da. Negros e territórios quilombolas no Brasil. (2012) Recuperado em 11 de maio de 2018 de: http://www2.marilia.unesp.br/revistas/index.php/cedem/article/view/2339/1962

Tavares, O. H. Teoria da Capilaridade Social. (2013) Recuperado em 11 de maio de 2018 de: http://www.midia.apmp.com.br/arquivos/pdf/artigos/2013_capilaridade_social.pdf

\section{Os autores:}

Andréa Aparecida Fernandes possui graduação em Psicologia pela Universidade Federal de Goiás (2014), Pós-Graduação em Saúde Mental e Atenção Psicossocial (2017) e Mestrado em Saúde e Educação (em andamento, UFU). Atualmente é professora da Centro Universitário Mário Palmério- UNIFUCAMP, email de contato: andreafernandes989@ hotmail.com

Lara Gonçalves Moreira graduanda em Psicologia pela Centro Universitário Mário Palmério- UNIFUCAMP, e-mail de contato: laragm99@bol.com.br

Laura Maria Mota Rosa graduanda em Psicologia pela Centro Universitário Mário Palmério- UNIFUCAMP, e-mail de contato: laura-mota@ hotmail.com

Laurem Nayane Mundim Rosa graduanda em Psicologia pela Centro Universitário Mário PalmérioUNIFUCAMP, e-mail de contato: lau.nayane@gmail.com

Vicente de Paulo da Silva graduando em Psicologia pela Centro Universitário Mário Palmério- UNIFUCAMP, e-mail de contato: vickimwyk@ gmail.com

Recebido em: 15/03/2019

Aprovado em: 29/06/2019 